\title{
The use of crude tall oil as feed-stock for alkyd resins
}

\author{
Paulo A. Z. Suarez, ${ }^{1 \star}$ Sandra Einloft ${ }^{2}$ Nara R. de S. Basso, ${ }^{2}$ Jonas A. Fernandes, ${ }^{2}$ \\ Ladimir da Motta, ${ }^{2}$ Lisandra C. do Amaral, ${ }^{2}$ Daniella G. Lima ${ }^{1}$ \\ ${ }^{1}$ Instituto de Química, Universidade de Brasília, CP 4478, 70910-904, Brasília-DF, \\ Brazil; Fax number ++556133074149; e-mail: psuarez@unb.br \\ ${ }^{2}$ Faculdade de Química/ PGETEMA, Pontifícia Universidade Católica do Rio Grande \\ do Sul, Av. Ipiranga 6681, 90619-900, Porto Alegre, Brazil; e-mail: einloft@pucrs.br
}

(Received: 29 December, 2006; published: 16 April, 2008)

\begin{abstract}
The synthesis of modified alkyd resins using a crude tall oil with a content of rosin acids of $39.8 \%$ is described. This material has the composition of fatty acids close to soybean oil, has low cost and is widely available being a forest product industrial residue. The synthetic route includes the reaction of tall oil and maleic anhydride, in the presence of the catalyst ( $\mathrm{LiOH})$, followed by polyesterification reaction steps, resulting in an alkyd resin with interesting properties. The acid value (AN) and viscosity were used to follow the reaction, and it appears to be dependent upon the polyalcohol used in the polyesterification step. A period of 15 hours was needed to yield a tack-free coating.
\end{abstract}

\section{Introduction}

The inks, paints and coatings industry has historically been a large user of renewable sources such as seed oils and wood derivatives primary because of their availability [1]. Nowadays, with the easy petroleum supply, inks, paints and coatings are largely manufactured using specially those resins derived from synthetic polymers, such as polyacrylates, polyurethanes and polyesters [1, 2], using petrochemical feedstock. However, due to the increasing energy demand, exhaustion of readily accessible petroleum in the future and environmental awareness, a shift back to emphasis on raw material from renewable sources for fuels and chemicals productions is becoming imminent [1].

Alkyd resins, which are largely used as binder in surface coatings, are usually manufactured by the polycondensation of polyols, polybase acid and vegetable oils as fatty acid source [3]. As well described in some recent reviews available in the literature [3-5], there are several protocols to prepare alkyd resins and two different methods are usually used: (i) alcoholysis of the vegetable oil using a polyol followed by esterification of the generated free $\mathrm{OH}$ groups with a polyacid; (ii) direct esterification of fatty-acids with polyols and polyacids.

It is well known that the properties of alkyd resins depend, in great extent, on the type of vegetable oil used [6]; soybean oil, castor oil, linseed oil, tung oil and tall oil the most common vegetable oil being used [3-5]. Indeed, the criterion of choice for the raw materials to produce the alkyd resin depends upon the desired properties for the final product, on the availability and on the economic viability.

It is worth mentioning that some attempts to use waste materials have recently been done in order to address environmental problems and also to reduce the cost of alkyd resins preparation. For instance, the use of polyethylene terephthalate as 
polyol source has been successfully used in the preparation of alkyd resins with different vegetable oils [7, 8].

Crude tall oil, which is a by-product of paper production from pine trees via the Kraft process $[9,10]$, is a mixture of rosin acids and fatty acids with large composition range. Distilled or refined tall oil is a fatty acid source, with composition closely resembling the soybean oil fatty acids, it meets the criteria of low cost and it is widely available being a forest product industry residue $[9,10]$. It is important to note that, due to the absence of linolenic acid [10], tall oil based resins have their colour retention increased when compared with other oils based resins. Thus, we think that crude tall oil is a potential source of fatty acids for the alkyd resin industry and, as far as we now, very few studies have been done in order to prepare resins using it [1]. In this work we describe the synthesis and properties of a modified alkyd resin which was obtained using crude tall oil with $39.8 \%$ of rosin acids.

\section{Results and discussion}

\section{Resin synthesis}

The crude tall oil used in the resin synthesis presented an AN value of $170.8 \mathrm{mgKOH}$ $\mathrm{g}^{-1}$ and Gardner Colour of 9 . This starting material has a high content of rosin acid (39.8\%).

Our first attempt to obtain an alkyd resin from crude tall oil was done using a traditional synthesis method. In this method, the polyesterification reaction was used to obtain an alkyd resin from crude tall oil (62.5\%), phthalic anhydride (17.0\%), maleic anhydride (5.2\%), pentaerythritol (10.7\%) and ethylene glycol (9.4\%). However, the obtained alkyd resin presented no interesting properties (AN 90 and a high viscosity).

Tab. 1. Formulations of alkyd resins starting materials and preparation reaction conditions.

\begin{tabular}{lcccccc}
\hline Composition (\%) & \multicolumn{7}{c}{ Entry } & & & \\
& 1 & 2 & 3 & 4 & 5 & 6 \\
\hline Tall oil & 62.5 & 62.5 & 62.5 & 63.7 & 50.1 & 31.8 \\
Soybean oil & - & - & - & - & 12.8 & 20.0 \\
Pitch & - & - & - & - & - & 12.7 \\
Phthalic anhydride & 17.0 & 17.1 & 17.0 & 22.3 & 22.8 & 22.5 \\
Maleic anhydride & 5.2 & 5.1 & 4.7 & 0.7 & 0,7 & 0.7 \\
Glycerin & - & - & - & 10 & 7.9 & 6.0 \\
Pentaerythritol & 10.7 & 10.8 & 10.9 & 9.9 & 10.5 & 11.0 \\
Ethylene Glycol & 9.4 & 9.5 & 9.5 & - & 0.6 & - \\
Total reaction Time (h) & 6.5 & 7.1 & 6.8 & 9.8 & 10.7 & 10.5 \\
Polyesterification (step a) & 1 & 2 & $1 *$ & & & \\
reaction Time (h) & 1 & The pentaerythritol was added two times: $5.45 \mathrm{~g}$ in the beginning of the polyesterification step(a) and \\
T5 g was added together with the phthalic anhydride at the end of $1 \mathrm{~h}$.
\end{tabular}

It is known from literature that the rosin acids react by Diels Alder reaction with dienophiles, such as maleic anhydride, to form tribasic acids, which are capable of 
reacting with polyols to form high molecular weight rosins [1]. The synthesis of alkyd resins described in literature was achieved using refined tall oil by first charging this oil (1000 parts by weight) into the reactor and heating at $235^{\circ} \mathrm{C}$, followed by the slow addition of maleic anhydride (80 parts by weight), and, after standing the reaction for 15-20 minutes, the phthalic anhydride (300 parts by weight) and glycerin (305 parts by weight) were added and the reaction ran at $270{ }^{\circ} \mathrm{C}$ until the desired AN value was obtained [10]. Based on this statement, we decided to react crude tall oil with maleic anhydride in the presence of $\mathrm{LiOH}$ at $235{ }^{\circ} \mathrm{C}$ for 0.5 hours before the polyesterification steps. Table 1 summarizes the formulations of synthesized alkyd resins and Table 2 the reaction conditions and the obtained resins properties. Note that using these reaction procedures (entry 1 of Table 2), the resulting alkyd resin showed different properties values $(\mathrm{AN}=26 \mathrm{mgKOH} / \mathrm{g})$ and a high viscosity of 1180 $\mathrm{Cp}$ ) than those described in literature for a modified alkyd resin using refined tall oil with $40 \%$ rosin acid (AN value in the range of $18-20 \mathrm{mgKOH} \mathrm{g}^{-1}$ and viscosity of 884 Cp) [10]. For this reason, some changes in the synthetic route steps (entries 2 and 3 of Table 1) were introduced, which allowed us to overcome our initial unsuccessful trend. Indeed, in spite of the composition of the starting material for reactions 1, 2 and 3 were almost the same, the resulted resins presented significant differences in viscosity and $\mathrm{AN}$, as can be depicted in Table 2, showing that with the change in synthetic route we could obtain alkyd resins with AN and viscosity values close to those reported in the literature [10].

Tab. 2. Properties of the resins obtained in the different polymerization reactions using $\mathrm{LiOH}\left(7.08 \times 10^{-3} \mathrm{~mol}\right)$ as catalyst.

\begin{tabular}{cccccccc}
\hline Entry & $\begin{array}{c}\mathrm{AN} \\
(\mathrm{mgKOH} / \mathrm{g})\end{array}$ & $\begin{array}{c}\text { Viscosity } \\
(\mathrm{Cp})\end{array}$ & $\begin{array}{c}\mathrm{H}_{2} \mathrm{O} \\
(\mathrm{g})^{\mathrm{a}}\end{array}$ & $\begin{array}{c}\mathrm{SC}(\%) \\
\mathrm{b}\end{array}$ & $\begin{array}{c}\text { Molar Mass } \\
\mathrm{Mn}\end{array}$ & $\mathrm{Mw}$ & \multicolumn{2}{c}{$\begin{array}{l}\text { Mw/M } \\
\mathrm{n}\end{array}$} \\
\hline 1 & 26.0 & 1180 & 62.6 & 53.4 & - & - & - \\
2 & 27.7 & - & 68.5 & - & - & - & - \\
3 & 18.3 & 977 & 67.1 & 54.6 & - & - & - \\
4 & 12.2 & 756 & 43.3 & 55.1 & 2310 & 23900 & 10.4 \\
5 & 10.2 & 589 & 31,5 & 54.9 & 2410 & 24900 & 10.3 \\
6 & 17.4 & 756 & 42.5 & 55.7 & 2400 & 30300 & 12.6 \\
\hline
\end{tabular}

Another try was to change the proportion between the maleic anhydride and the tall oil in the initial step of reaction (entry 4), arriving to a better resin with $A N=12.2$ $\mathrm{mgKOH} \mathrm{g}^{-1}$ and a viscosity of $756 \mathrm{Cp}$. Note that, in this reaction, we have changed the ethylene glycol by glycerin to be sure of obtaining a good drying time to the resin. By changing the amount of maleic anhydride (from $5 \%$ to $0.7 \%$ ) in the first step of reaction, we obtained an alkyd resin with a small AN value. A similar behaviour was obtained in the preparation of a resin from maleinized rubber seed oil [11-12], were the AN was observed to increase with the maleic anhydride content (for example, AN of $5.58 \mathrm{~g}$ was obtained using $2 \%$ of maleic anhydride and AN of 10.36 when $10 \%$ of maleic anhydride was used). When the crude tall oil was partially substituted by soybean oil (see entries 4 and 5 of Table 2), no changes in the AN were observed. However, when the crude tall oil was partially substituted by soybean oil and also by pitch (see entries 5 and 6 of Table 2), an augmentation of AN was verified. We 
observed for reaction 5 that the addition of soybean oil resulted in an alkyd resin with properties extremely close than that obtained only with tall oil. The aim of addition of soybean oil was to improve the colour characteristics of the alkyd resin obtained by lightening de coloration, but no sensible change was observed. As shown in Table 2, the non-volatile content for all resins was analyzed and the result varies in the range between $53.4 \%$ and $55.7 \%$.

\section{Resin characterization and curing performance}

It can be also observed from Table 2 that the resins obtained in reactions 1, 2 and 3 were significantly much more viscous than those obtained in reactions 4,5 and 6 (see Table 2). It is worth to mention that the less viscosity observed when glycerine was used in the composition instead of ethylene glycol is probably related to the higher degree of crosslinking in the glycerine based resin (see Table 2). In fact, after 6 hours the reactions 1, 2 and 3 were stopped since their high viscosity blocked their proper stirring, whereas it was possible to keep reactions 4,5 and 6 running for 10 hours. As a consequence, the AN and DP values, which behave very close for all reactions in the first 6 hours, achieved better values for the reactions 4,5 and 6 at the end of 10 hours, as can be seen in Figure 1 and Figure 2.

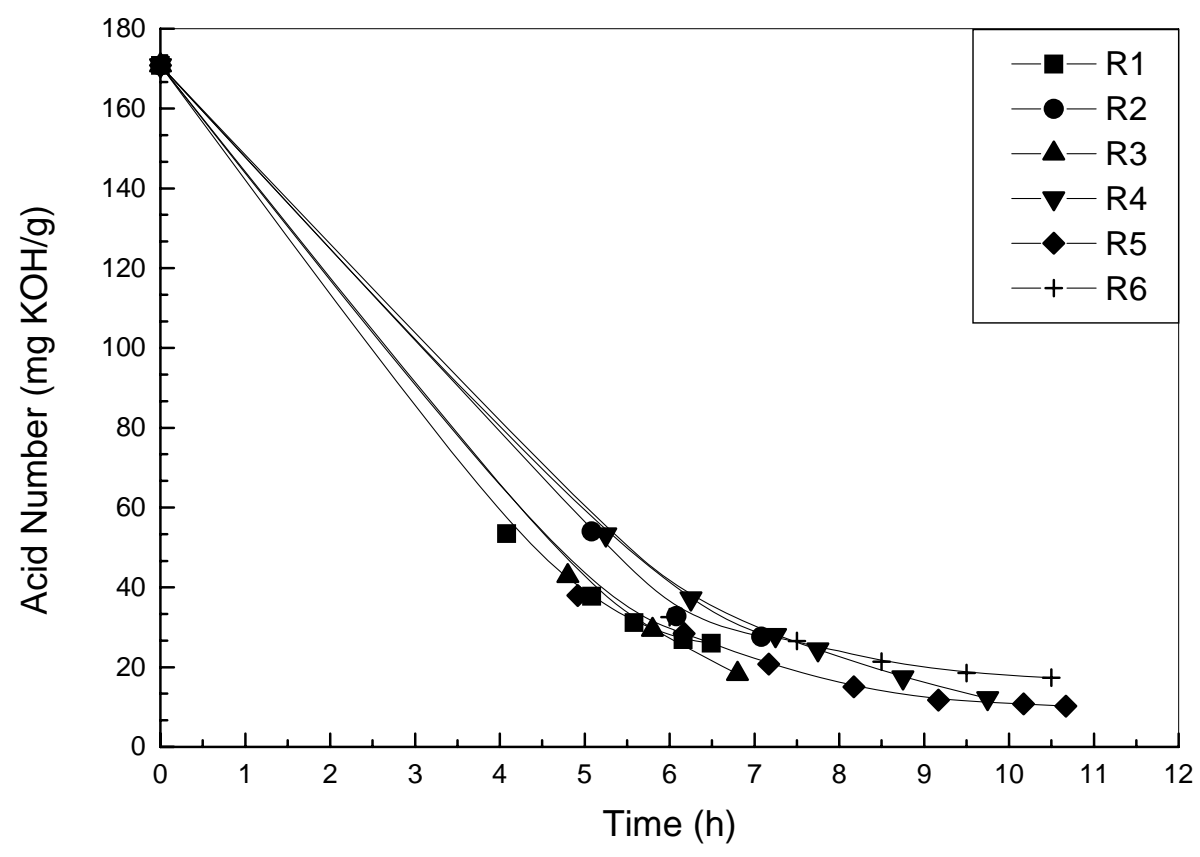

Fig. 1. Variation of the acid number during the alkyd resin preparation reactions described in Table 1 and Table 2.

Although their lower degree of esterification during the reactions 1,2 and 3 the amount of recovered water was superior to that for the reactions 4,5 and 6 . Since the crosslink degree in these resins is expected to be higher when using glycerine, and thus their capability to occlude water, this behaviour is probably due to difficulties in water removal. It can also be seen in Figure 1 that the acid number decreases with reaction time, being this variation more accentuated for the initial hours. This behaviour has been already described in the literature $[6,11,13]$ and was explained 
in terms of different reactivity of primary and secondary hydroxyl groups of glycerol. A primary hydroxyl group reacts faster than a secondary one, so the faster period of decrease in acid number is probably attributed to the reaction of the primary hydroxyl groups and the slow one to the reaction of secondary hydroxyl groups.

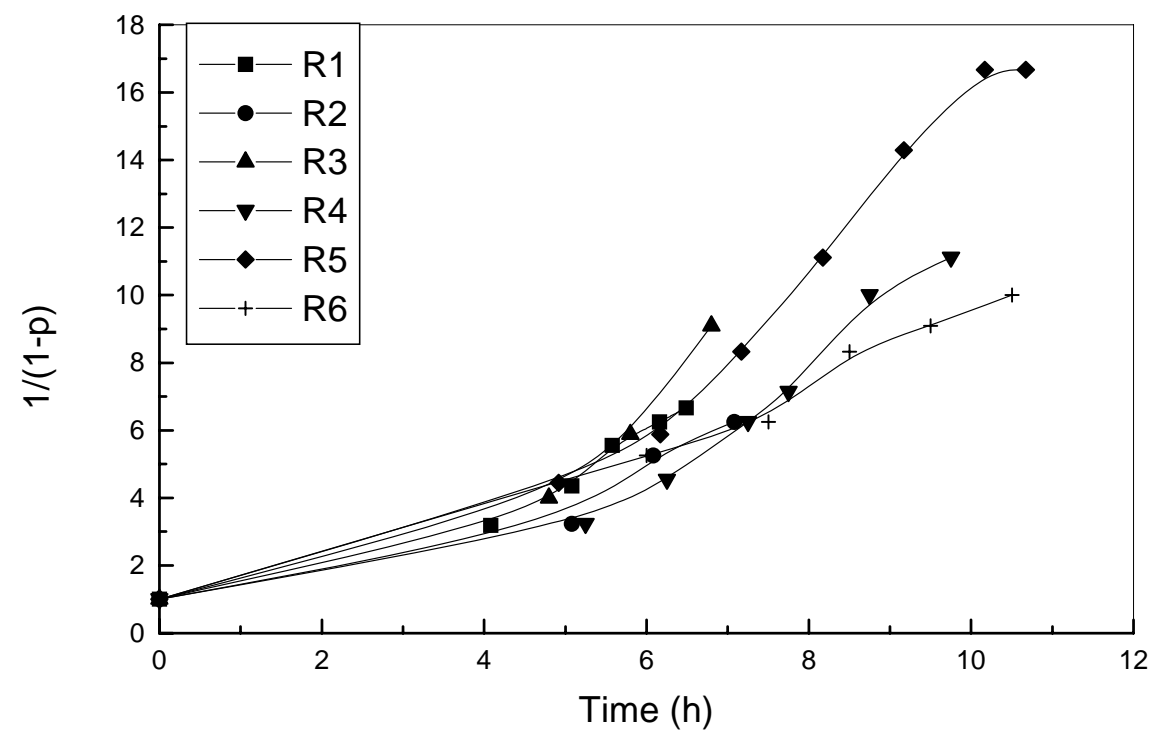

Fig. 2. Variation of the degree of polymerization during the alkyd resins preparations described in Table 1 and Table 2.

The reactions 4,5 and 6 , which presented better $A N$ and viscosity results, had their molar mass and drying characteristics evaluated. Indeed, as depicted in Table 2, the resins obtained in reactions 4,5 and 6 showed a great degree of polydispersity $\left(M_{w} / M_{n}>10\right)$, with $M_{n}$ between 2300 and $2400 \mathrm{Da}$ and $M_{w}$ between 23900 and 30300 $\mathrm{Da}$. For these three resins, the drying characteristics showed that a drying time of 15 $\mathrm{h}$ was needed to yield a tack-free coating.

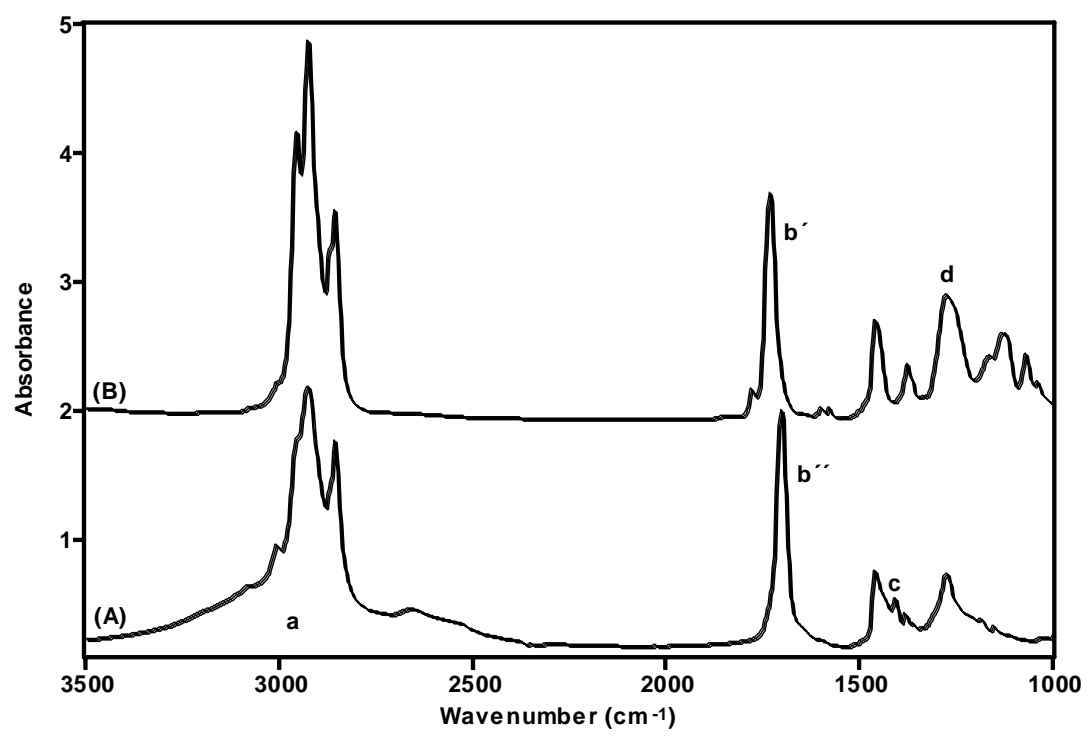

Fig. 3. Spectra obtained for the tall oil (A) and reaction 4 (B). 
The polyesterification reaction was evidenced by infrared analysis. Figure 3 shows the spectra of the crude tall oil with $39.8 \%$ of rosin acid and the spectra of reaction 4 . From Figure 3 in the tall oil spectra (A) a broad band in the region a, between 2500 and $3500 \mathrm{~cm}^{-1}$, characteristic of carboxylic acids and attributed to $\mathrm{O}-\mathrm{H}$ bond stretching can be described, which completely disappears in the spectra of reaction 4. Figure 2 shows also the shift of the $\mathrm{C}=\mathrm{O}$ stretching from $1701 \mathrm{~cm}^{-1}$ in the tall oil to $1731 \mathrm{~cm}^{-1}$ in the reaction 4 product (see bands $\mathrm{b}^{\prime}$ and $\mathrm{b}^{\prime \prime}$ ), strongly indicating the transformation of the acid in ester. The disappearing of the band in $1406 \mathrm{~cm}^{-1}$ (see band $\mathrm{c}$ of Figure 3 ) in the reaction product, which can be attributed to the $\mathrm{C}-\mathrm{O}-\mathrm{H}$ out of the plane stretching, and the absorbance increase of the band in $1275 \mathrm{~cm}^{-1}$ (see band $d$ of Figure 3), which may be attributed to C-O stretching, confirms the ester formation and the acid consumption.

In summary, we have described a new method to synthesize alkyd resins using crude tall oil with $39.8 \%$ of rosin acid. The resulting resin showed adequate AN, viscosity and drying properties for commercial use. These properties are also in good agreement with those described in literature [10]. It is important to note that the synthetic route seemed to determinate the resin properties obtained.

\section{Experimental part}

\section{Materials}

All chemicals were acquired from commercial sources (Aldrich) and utilized without any further purification. Edible soybean oil was purchased (Bunge Brazil) and used as received. Pitch and Tall oil were obtained from Tintas Renner S. A. and used without any treatment. As attested by this company, the composition of tall oil was 60.2 of fatty acids (Palmitic 6\%, Palmitoleic 1\%, Stearic 1\%, Oleic 41\%, Linoleic 40, others $11 \%$ ) and 39.8 rosinic acids.

\section{Polymerization Reactions}

All polymerization reactions were carried out in a $2 \mathrm{~L}$ reactor, consisting of a four neck round-bottom flask equipped with an air drive stirrer, a thermocouple, a tube test receiver, nitrogen inlet tube and a Dean and Stark apparatus connected to a reflux condenser. Xylene was used as azeotropic solvent. The reactor was heated by an electrical heating mantle connected to a temperature controller which has the temperature monitored by a Pt 100 thermocouple submerged inside the reaction medium. The formulations of alkyd resins synthesized by the process described below are listed in Table 2. Reaction 1,4,5,6 followed the synthetic route described below. In reactions 2 and 3 we introduced some changes described in the results and discussion section.

Step 1- Anhydride reaction: tall oil and the catalyst $\mathrm{LiOH}\left(7.08 \times 10^{-3} \mathrm{~mol}\right)$ were heated to $235{ }^{\circ} \mathrm{C}$ and then the maleic anhydride in the proportion shown in Table 2 was added and the reaction was kept at this temperature for $30 \mathrm{~min}$.

Step 2- Polyesterification reaction: a) The temperature was reduced to $190{ }^{\circ} \mathrm{C}$ and pentaerythritol, in the proportion shown in Table 2, was added and then the temperature was increased to $260{ }^{\circ} \mathrm{C}$ and the reaction was maintained at this temperature for the desired time. b) The temperature was lowered to $190{ }^{\circ} \mathrm{C}$ and phthalic anhydride, glycerine and/or ethylene glycol (see Table 2 for composition) were added and the temperature was increased slowly to $235^{\circ} \mathrm{C}$ during $100 \mathrm{~min}$. 
After this step the formation of water was observed and the reaction was followed by the evaluation of acid number and the viscosity. The acidic number (AN), i. e. the total concentration of the carboxylic groups, was measured by diluting about $1.0 \mathrm{~g}$ of the sample to $50 \mathrm{~cm}^{3}$ of a mixture of ethanol and xylene (1:1). The sample was heated until fusion without boiling, and then titrated using a $\mathrm{KOH}$ methanol solution $(0.1 \mathrm{~N})$ and phenolphthalein as indicator, at room temperature. The acid number (expressed in $\mathrm{mgKOH} \mathrm{g}^{-1}$ ) was calculated [10] by $\mathrm{AN}=(\mathrm{V} \times 56.1 \times \mathrm{N}) / \mathrm{P}$, were $\mathrm{V}$ is the volume (in $\mathrm{mL}$ ) of the titrate liquid, $\mathrm{N}$ the normality of titrate liquid and $\mathrm{P}=$ sample mass. The viscosity was determined by Gardner method according to ASTM D 154589 standard procedure. Note that, according to this method, all the samples were previously diluted to achieve $55 \%$ of non-volatiles using an ethanol and xylene mixture (1:1). The reaction time was defined as the time from the beginning of reaction until the last AN evaluation.

\section{Resin characterization}

The obtained resins were characterized by FTIR, GPC, viscosity and acid number. FTIR spectra were obtained on a Bruker Equinox 55, and the spectra correspond to the sum of 64 scans at a $4 \mathrm{~cm}^{-1}$ spectral resolution. Molecular weight distributions were determined using ASTM D 3593 standard method in a high temperature chromatograph Waters $150 \mathrm{C}$, equipped with differential optic refratometer equipped with three Styragel columns, using THF as solvent. The samples were injected with flow of $1,0 \mathrm{~mL} \mathrm{~min}^{-1}$ at $140{ }^{\circ} \mathrm{C}$. The universal curve calibration was elaborated with monodisperse polystyrene and linear polyethylene standards, between $495 \mathrm{~g} \mathrm{~mol}^{-1}$ and $8,420,000 \mathrm{~g} \mathrm{~mol}^{-1}$. Viscosity and acid number experiment were determined using standard method (ASTM D 1545-89 and D 465-9, respectively).

To evaluate the drying time, a mixture of each resin with $60 \%$ in volume of turpentine, $0,43 \%$ of $\mathrm{Pb}$ (octoate), $0,35 \%$ of $\mathrm{Mn}$ (octoate) and $0,28 \%$ of Co(octoate) was prepared. The mixtures were applied to a glass substrate using a standard film applicator, with a film thickness of $100 \mu \mathrm{m}$. The extent of reaction was calculated by $P A=\left(C_{0}-C_{t}\right) / C_{0}$, and the average degree of polymerization calculated by $D P=(1-$ $P A)^{-1}$ (where $C_{o}$ is the initial acid value and $C_{t}$ is the acid value after reaction time), as described in literature $[6,11]$.

\section{Acknowledgements}

Financial support by PUCRS, FAPERGS, Tintas Renner S.A and FINEP-CTPETRO is grateful acknowledged. JAF, LCA, DGL, SE and PAZS thank CAPES and CNPq for a research fellowship.

\section{References}

[1] Chen, G.F. Prog. Org. Coat. 1992, 20, 139.

[2] Van der Walle, G.A.M.; Buisman, G.J.H.; Weusthuis, R.A.; Eggink, G. Int. J. Biological Macromol. 1999, 25, 123.

[3] Suarez, P.A.Z.; Meneghetti, S.M.P.; Meneghetti, M.R.; Wolf, C.R. Quim. Nova 2007, 30, 667.

[4] Guner, F.S.; Yagcı, Y.; Erciyes, A.T. Prog. Polym. Sci. 2006, 31, 633.

[5] Holme, I. Surface Coatings Int. B: Coatings Trans. 2006, 89, 1476.

[6] Aigbodion, A.I.; Okieimen, F.E. Ind. Crops Prod. 2001, 13, 29. 
[7] Baldissera, A.F.; Valério, C.E.S.; Basso, N.R.S.; Guaragna, F.; Einloft, S.; Tessier, M.; Fradet, A. Quim. Nova 2005, 28, 188.

[8] Dullius J.; Ruecker, C.; Oliveira, V.; Ligabue, R.; Einloft, S. Prog. Org. Coat. 2006, $57,123$.

[9] Coll, R.; Udas, S.; Jacoby, W.A. Energy \& Fuels. 2001, 15, 1166.

[10] Zachary, L.G.; Bajak, H.W.; Eveline, F.J. (eds), Tall Oil and Its Uses, New York: McGraw-Hill, 1965.

[11] Aigbodion, A.I.; Okieimen, F.E. Eur. Polym. J. 1996, 32, 9, 1105.

[12] Aigbodion, A.I.; Okieimen, F.E.; Obazee, E.O.; Bakare, I.O. Prog. Org. Coat. 2003, 46, 28.

[13] Goldsmith, H.A. Ind. Eng. Chem. 1948, 40, 1205. 